\title{
Status of HCI and Usability Research in Indian Educational Institutions
}

\author{
Pradeep Yammiyavar \\ Professor, IIT Guwahati, Guwahati, Assam-781039, India \\ pradeep@iitg.ernet.in
}

\begin{abstract}
HCI is an emerging area of great potential in India. While Design schools were already advocating it as part of Design education since a decade, it has yet to consolidate itself as an independent area of specialization in a learning institution. Computer science and Information technology institutions have started taking interest in HCI. There is urgency for training more researchers in this filed. This paper traces briefly the evolution of HCI in educational institutions in India. It highlights through samples of research work done in one or two institutions such as IITG.
\end{abstract}

Keywords: HCI education, Research, Design, Computer Science, Information Technology.

\section{Introduction}

Long before the advent of Computer Science discipline on the Indian educational scene, Design schools in India were already teaching and practicing one or the other forms of User Centered Design (UCD) that constitutes the core of today's HCI / User Experience (UX) / Usability Engineering (UE) / Interaction Design (ID). Else where in the world, HCI is more associated with Computer Science (CS) \& Information Technology (IT) disciplines rather than Design. For the Computer Science researchers the ' $\mathrm{C}$ ' in $\mathrm{HCI}$ is of more interest than ' $\mathrm{H}$ '. For the Design schools ' $\mathrm{H}$ ' is the focus in HCI. Both these schools are of course interested in the 'I' of HCI. Indian Design schools have a lead over their Computer Sciences counterparts in HCI / UX / UE / ID when it comes to Human Interactions and ICT applications. Eventually, like it has happened else where in the world in India too, HCI will be focused upon more by IT and CS institutions. CS \& IT groups in India are now wakening up to the potential of HCI as a specialization. The Information Technology \& Computer Science departments across the country are larger in number than Design departments / schools. However in India it is the Design Schools that have formed the foundation for skilled and trained human resources in this field. Will they be able to maintain the lead is an appropriate question to raise now?

Which of the two disciplines - CS or Design should this activity associate itself with - is the moot question we in India will soon be facing. The ' $\mathrm{H}$ ' in $\mathrm{HCI}$ needs to be given as much consideration as ' $C$ ' by $\mathrm{CS}$ researchers. Like wise the ' $\mathrm{C}$ ' in $\mathrm{HCI}$ needs to be integrated with the design curriculum by Design Schools. Computer Science and Design Schools need to work together on the 'I' i.e. they need to 
'Interact' with each other much more. The HCI community needs to be prepared with an answer and an action plan to avoid a confused identity for this emerging discipline in India. International trends in published literature indicate that this activity is more a preserve of Computer Science and Information Sciences fields even though the contributors /authors themselves come from backgrounds as varied as Psychology, Ethnography, Design and Engineering amongst others. Else where Usability professionals $[1,2,3,4,5]$ have argued for a multidisciplinary approach to HCI citing reasons such as amalgamation of many disciplines. While the argument is valid, continuing to associate HCI as loosely knit coming together of disciplines (multidisciplinary) is probably preventing the field from emerging as a new discipline on its own right. Only those Design schools making paradigm shifts in their myopic vision will be the ones to collaborate with and lead the IT and CS professionals in forming a new discipline that has Humans at one end and machine computation / environment at the other.

\section{The Evolution of the HCI in Indian Educational Institutions}

ICT related educational programs in Indian institutions are offered under a wide range of disciplines such as Commerce, Management, Information Science, Computer Science, Engineering, Information Technology and Creative Design. Academic activity surrounding HCI as a serious specialization in Design can be traced back to work done, either in Ergonomics of products or in Interface design in Graphics, in three or four educational institutions. However the first dedicated Usability Engineering Research laboratory in a higher educational institution to admit research students was initiated in IITG in the year 2002 [3,4]. This laboratory accepted its first PhD scholar and started offering courses in HCI, UX, UCD \& Interaction Design in 2003. Since then over ninety (90) B.Des undergraduates, Ten (10) M.Des Postgraduates and one $\mathrm{PhD}$ have successfully specilised in this area from IITG which has a $100 \%$ placement record in HCI since 2002 for its Usability Engineers cum Design alumni. Many of them pursued higher studies in HCI at the Masters and PhD levels and are now working as Usability experts all over the world.

\subsection{Illustrative List of Some Recent Research, Design and Development Projects Completed at IITG}

- Extending Mobile as a Networking Medium for Educational Campuses

- Study of hand gestures as a mode of interaction and its future application Scenarios

- A tangible product to enhance real time user experience of enjoying music using kinesthetic interactions.

- Speech Based Mobile Interface for the Textually Low Literate

- User Centered Design of a Collaborative Work Environment in an Educational Scenario using Multiple Mice Inputs

- An Artificially Intelligent Recommender for enhancing user's browsing experience. 
- Role of Non-verbal communications in User Interactions and Demonstration through Gesture driven interfaces.

- Interactive Information Platform for Remote Health Care

- Study of Mobile as a future strategic advertising medium in India

- ICT in computer supported collaborative learning: some experiments at the school level

- Interactive Digital Signage system design for IITG campus

- An online aptitude testing system for admitting students in design program

- A multimedia repository for design projects - A Knowledge Management approach

- A Graphical User Interface based Remote Public Bus Transport Management System for Guwahati city.

- An Indian Culture Sensitive Tangible Social networking System.

- Design \& Development of a virtual counselor - a Knowledge management approach

\subsection{Some of the Upcoming Research Areas Initiated at IITG}

- Multi lingual and pan cultural solutions for device interactivity - Developing heuristics \& norms for GUIs in Indian contexts

- Development of non-invasive, Gesture driven, interfaces is another potential area being planned in Ubiquitous computing under this research topic.

- Educational Technology \& E -Learning systems: Mobile based e learning systems \& Collaborative learning environments

- Knowledge Management

- Digitally enabled living and working environments: Energy and ecology issues in Building systems and Urban Infrastructure through the application of computers.

The uniqueness of the IITG experience in HCI education has been its multidisciplinary as well as interdisciplinary nature incorporating, Design, Social Sciences, Computer Sciences and IT within its curriculum [3, 4]. Figures 1 and 2 illustrate some interaction design and HCI projects executed at the IITG's - Usability Engineering Lab. Figure 3 illustrates Usability testing sessions at the UE lab - IITG for an Interactive board based Mathematical learning software.

By 2006 and 2008-09 other institutions like National Institute of Design (NID) [14] \& Industrial design Centre -IITB (IDC) started offering specific degree programs in New Media Design and Interaction Design. NID and IDC had been teaching in this area for a decade, but as part of Design, and not as specialized HCI streams. In general, design schools in India prefer to use the term "Interaction Design" to label this area $[2,5]$. The first awarded PhD in HCI to a Designer was by Birla Institute of Technology and Science in 2005 [6]. Besides the above mentioned institutions, IT Institutions like the Indian Institutes of Information Technologies - IIITs, [9], CDAC (Centre for Development of Advanced Computing) and Computer Science Departments of Universities, have now initiated research activities in HCI. Several engineering institutions like VIT- Pune, IIIT - Hyderabad, ISIM - Mysore and many others 


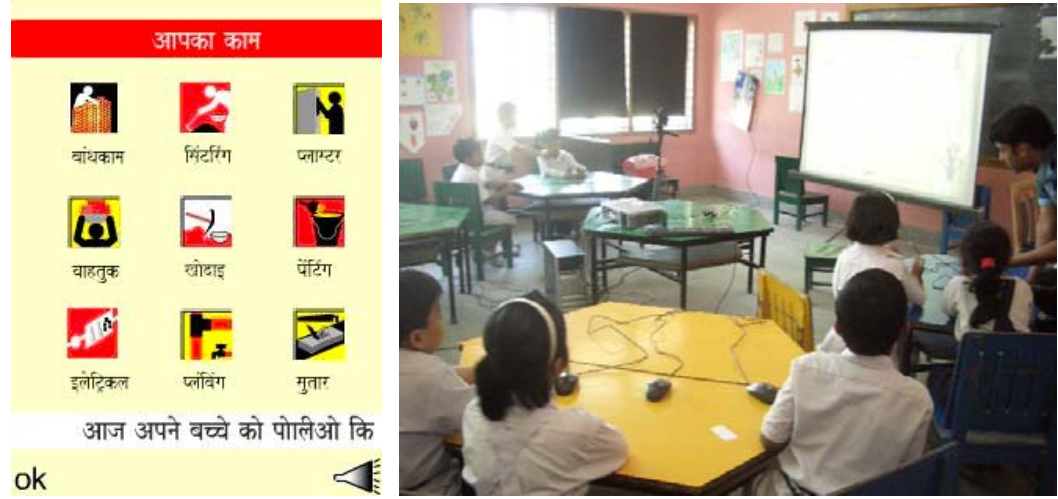

Fig. 1. (a) Mobile phone interface for Construction trade workers (b) Interface for collaborative learning system using multiple mice in a class room
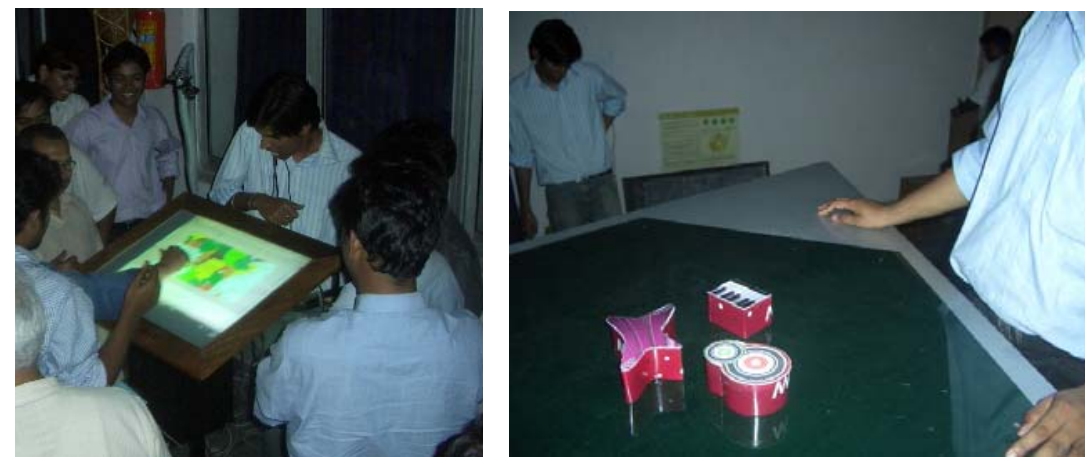

Fig. 2. (a) Gesture Interface prototype in operation (b) Interactive music table
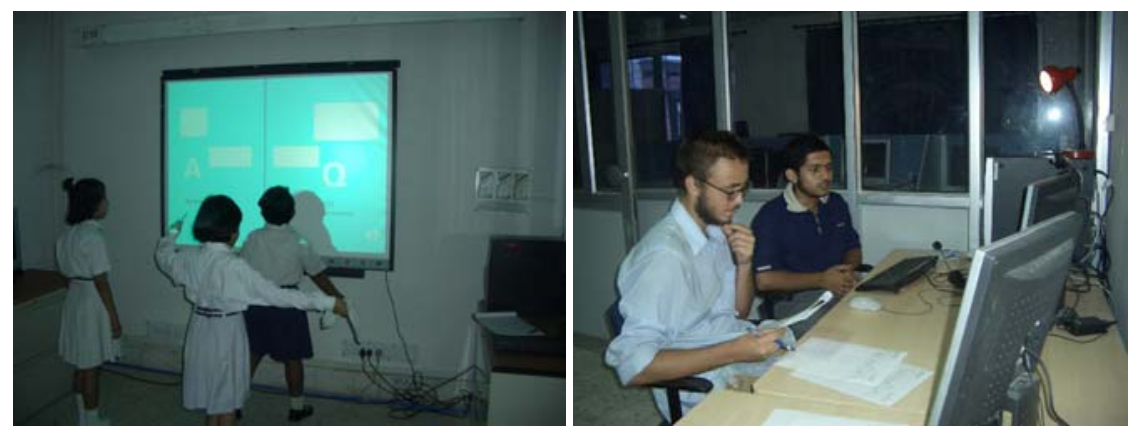

Fig. 3. Usability testing sessions at UE lab - IITG (a) Interactive Mathematics Learning interface - an E learning content development project. (b) Protocol Analysis session on Interfaces. 
through out India are now offering HCI related subjects in their curriculum A large number of Indian students have also started acquiring Masters and PhDs in HCI from institutions abroad from year 2000 onwards.

\section{Usability Practice in Industry}

As a rich pool of $\mathrm{HCI} / \mathrm{UE} / \mathrm{UX} / \mathrm{UCD}$ talent in a very niche area of IT starts growing in size, the Indian IT industry has been quick enough to spot it and offer service and expertise to IT companies the world over. The IT industry too has been actively practicing and evangelizing Usability as an important part of the product being delivered to the costumers. Every big corporate name from IBM to NOKIA to Honeywell to GOOGLE and many others have offices in India. Most of them by now have Usability teams working alongside Software teams. Along with the multinational corporations it is the medium and small firms that are pushing the Usability envelope by sheer enthusiasm and hoping for the business model to click. Professionals in HCI come from diverse backgrounds ranging from Design, Arts, Engineering, Information Science and Management. In 2006 the most comprehensive and useful survey [7] that were carried out gives an overall view of the usability profession in India. A whole range of job titles are used by the companies. However there is a dearth of $\mathrm{PhD}$ qualified professional researchers. Apart from educational institutions various associations managed by highly dedicated and enthusiastic usability professionals are active in India. Attempts are constantly being made by these associations to form an apex association for the Indian Usability professional as seen from active on line Usability discussion forums.

\section{Research Collaborations in Usability: Areas, Topics and Events}

India has just started its journey in this Design area of HCI and Usability. Institutions involved in serious research in Usability are few in number with IITG having taken the lead since 2002. IITG has over 60 publications in Journals / Refereed International and National conferences besides winning International awards for its research and product designs $\mathrm{HCI} / \mathrm{UX} / \mathrm{ID}$ which it labels under a single nomenclature of 'Usability Engineering' (UE). Many of the publications were the outcome of the Cultural Usability (CULTUSAB) project that was initiated in collaboration with Copenhagen Business School [10]. A number of other European Institutions too have been collaborating with IITG by offering internship to IITG HCI students. Often the students continue working on their internship projects after returning to India. Other institutions like CDAC, IIT Bombay, IIITH too have a significant track record of research output as measured by publications, industry interactions and international research collaborations.

Institutions like NID, IIITs, CS departments of IITs \& IISc as well as university departments such as Psychology \& Cognitive Science hold tremendous potential to engage in research activity in Usability and HCI. There is a dearth of trained researchers. India probably has less than 10 researchers with a $\mathrm{PhD}$ actively researching in $\mathrm{HCI} / \mathrm{UE} / \mathrm{UX} / \mathrm{ID}$. 
The first conference on HCI, Systems Usability, and User-Centered Design was held in Bangalore on December 6 and 7, 2004 under the aegis of the Indo-European Systems Usability Partnership (IESUP), in cooperation /association with the Computer Society of India, the British Computer Society / HCI Group, ACM / SIGCHI, and the International Federation for Information Processing (IFIP).[8] Since then more than 10 international, national conferences and events have taken place in a short span of 5 years mainly in Mumbai, Bangalore, Hyderabad, Guwahati and Pune. The second IEEE International conference on Intelligent Human Computer Interaction is scheduled in January 2010 at IIIT, Allahabad. [9] followed by another international event at IIT Mumbai in March 2010. International collaborations like the CULTUSAB project between Copenhagen Business School, IITG and Chinese Academy of Science as well as the IESUP and IFIP have played a catalytic role for research activity in HCI in India. Similar collaborations are being planned between German institutions and IIT Madras which is setting up a new entity in IT with is likely to have HCI as a focus along with other areas.

Based on a survey of information depicted in the institutional websites and based on the list of publications the following categories / areas of research can be broadly identified as those that are currently being pursued in Usability in India. By no means is this list complete in its representation.

\author{
Multi Media Content \\ Digital Conservation and Library \\ Language tools \\ E-Learning systems, contents and Tools \\ E- Governance \\ Medical applications of ITC \\ Culture \\ Mental Models \\ User personality, emotions, attitudes in HCI \\ Usability testing of software and hardware products. \\ Information Architecture and Graphic User Interfaces \\ Mobiles \& PDA Interfaces. \\ Information Systems \\ Graphic User Interfaces \\ ICT in Social Systems \\ Retail, Banking and Service industry \\ Cognitive Models for Human Computer Interaction \\ Signal and Vision Processing \\ Language Processing \\ Intelligent Methods \& Interfaces \\ Computational Semantics
}

\title{
5 Conclusions
}

Vast unexplored potential exists in India for Usability Research. The Indian environment offers a unique context for live research especially in Cultural issues. It also has the world's largest pool of IT professionals. For Usability /HCI / UX /UE /ID to 
evolve into an independent branch of study in educational institutions more graduates, postgraduates and PhDs are needed to be produced. Institutions like NID, IIITs, CS departments of IITs \& IISc as well as university departments such as Psychology \& Cognitive Science hold tremendous potential to engage in research activity in Usability and HCI. Design Departments need unshackle themselves and leap forward to keep up the pace of the good work done so far and set the direction for the future. There is a dearth of trained researchers. More national and international research collaborations need to happen. Educational institutions need to already have in place a curriculum of the next 5 years.

\section{References}

1. Yammiyavar, P.: HCI and Usability Research in Indian Educational Institutions. In: Katre, D., et al. (eds.) HWID - Pre Conference proceedings -Working Conference on Usability in Social, Cultural and Organizational Contexts, CDAC-IFIP, Pune (2009) ISBN 978-81-909383-0-3

2. Joshi, A.: Interaction Design in India - Past, Present and Future. In: CHI 2004, Vienna, Austria, April 24-29. ACM, New York (2004)

3. Yammiyavar, P.: Development of an Interdisciplinary curriculum- instructional activities and examples from Usability engineering and HCI courses at IITG. In: HWWE 2006; Proceedings, IIT Guwahati, Assam. International Ergonomics Conference HWWE. 05 IITG (2005)

4. Yammiyavar, P.: Incorporating HCI in the curriculum - a case study. CSI Communications 29(3) (September 2005 )

5. Chavan, S.: HCI in India 2008. HCI International News, Number 32 (November 2008), http: / / www.hci-international.org

6. Katre, D.S.: Visualisation of Interface Metaphor for Software: an engineering approach. PhD Thesis, Birla Institute of Technology and Science Pilani (2005)

7. HCI Professionals Salary Survey 2006 - India; Usability Professional's Association, Hyderabad (2006), http: / / www . upahyderabad.org

8. Interactions, September - October 2005; ACM 1072-5220/05/0900

9. Indian Institute of Information Technology, Allahabad web site, http://hci.iiita.ac.in

10. Cultural Usability project at CBS (retrieved on 2 11-09), http: / /www. culturalusability.com

11. HCI groups (retrieved on 5 th November 09), http: / / tech.groups.yahoo.com/group/hciidc/

12. Iyengar, J.: For a User Friendly Interface. Financial Express, October 6 (2007)

13. Call for HCI Conference (retrieved on 4th November 09), http: //www. indiahci.in

14. HCI Vistas On line journal accessed at, http: / /www . hceye. org

15. http://bangalore.nid.edu/academics_dde.htm (retrieved on 5th November 2009) 